\title{
Integrated Management of Childhood Illness in Lahej, Yemen: a qualitative analysis from the perspective of health providers
}

H.O. Basaleem ${ }^{7}$ and R.M. Amin ${ }^{2}$

$$
\begin{aligned}
& \text { التدبير العلاجي المتكامل لأمر اض الطفولة في لَّج - اليَمَن: تحليل كيفي من منظور مقدمي الخدمات الصحية }
\end{aligned}
$$

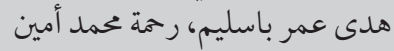

الخلاصة: استطلعت الباحثتان في هذه الدراسة النوعية مفاهيم مقدِّمي الخدمات الصحية في محافظة لحج، في اليمن، حول استـراتيجية التدبير

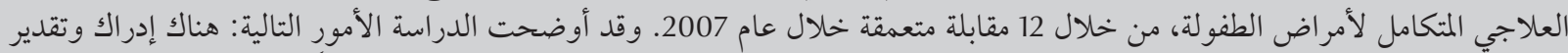

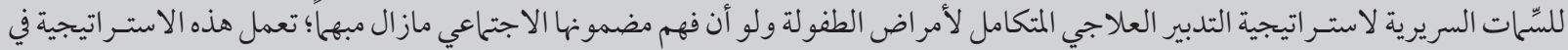

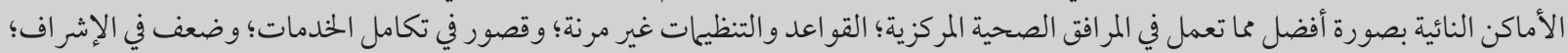

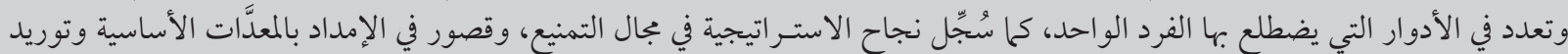

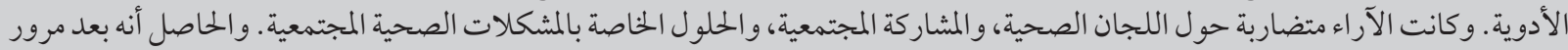

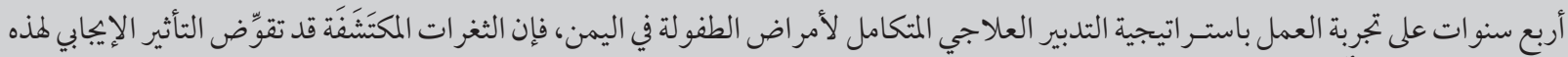

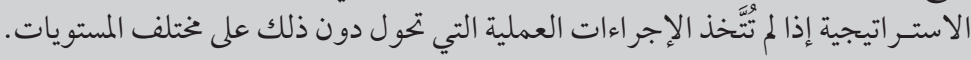

ABSTRACT Health providers' perceptions about the Integrated Management of Childhood IIIness (IMCI) in Lahej governorate, Yemen, were explored in a qualitative analysis of 12 in-depth interviews in 2007. The following themes emerged: appreciation of clinical aspects of $\mathrm{IMCl}$ but unclear understanding about community IMCI; $I \mathrm{MCl}$ working better in peripheral than central health facilities; inflexible rules; lack of integration of services; poor supervision; multiple roles for one person; success of immunization; basic equipment and drug supplies deficient; conflicting views about health committees and community participation; and solutions for community health problems. After 4 years of $\mathrm{IMCl}$ experience in Yemen, the gaps identified would endanger the positive influence of $\mathrm{IMCl}$ unless action is undertaken at different levels.

Prise en charge intégrée des maladies de l'enfant à Lahej (Yémen) : une analyse qualitative du point de vue des prestataires de soins de santé

RÉSUMÉ Le point de vue des prestataires de soins de santé concernant la Prise en charge intégrée des maladies de l'enfant (PCIME) dans le gouvernorat de Lahej (Yémen) a été étudié au cours d'une analyse qualitative composée de douze entretiens approfondis, réalisés en 2007. Les thèmes suivants ont été dégagés : les aspects cliniques de la PCIME sont appréciés mais la composante communautaire de la PCIME est mal comprise ; la PCIME fonctionne mieux dans les établissements de santé périphériques que dans les établissements de santé centraux ; les règles sont inflexibles ; les services ne sont pas suffisamment intégrés ; la supervision est médiocre ; une même personne doit endosser plusieurs rôles ; la vaccination a été une réussite ; les équipements de base et l'approvisionnement en médicaments essentiels sont insuffisants ; des opinions divergentes ont été exprimées au sujet des comités sanitaires et de la participation communautaire; et des solutions pour les problèmes de santé de la communauté doivent être recherchées. Après quatre années d'expérience de la PCIME au Yémen, les lacunes identifiées pourraient compromettre l'influence positive de la stratégie si une action n'est pas menée à différents niveaux.

${ }^{'}$ Department of Community Medicine and Public Health, Faculty of Medicine and Health Sciences, University of Aden, Aden, Yemen (Correspondence to H.O. Basaleem: hudabasaleem92@yahoo.com).

${ }^{2}$ Department of Community Health, University Kebengsaan Malaysia, Kuala Lumpur, Malaysia.

Received: 22/06/08; accepted: 21/09/08 


\section{Introduction}

The Integrated Management of Childhood Illness (IMCI) initiative is an evidence-based strategy developed to improve the management of childhood illness in places with high child mortality [1]. It gives families access to the key interventions for child survival and healthy growth and development by bringing together several life-saving interventions of proven effectiveness in one integrated package [2].

The IMCI strategy has 3 components: improving case management and communication skills of health providers; strengthening the health system; and improving family and community practices (referred to as communityIMCI or C-IMCI) [1-4]. While improving health provider skills is the most widely implemented component experience shows that all 3 components of ICMI are linked, and support each other to impact on child health [5-7].

In Yemen, IMCI was formally introduced at the end of 1998 as a suitable strategy to meet the needs of the primary health care system, which was facing difficulties in integrating vertical child care programmes. The first IMCI training was conducted in 2002 to launch the introduction phase of the strategy, which lasted for 1 year, followed directly by the expansion phase without passing through the early implementation phase. The focus of the Yemeni IMCI strategy has been on the 3 main components [8]. To date, no study has addressed IMCI implementation in Yemen. The present study was undertaken to explore the perceptions of health providers about the IMCI strategy in Lahej governorate, Yemen, since its implementation in 2003.

\section{Methods}

\section{Study setting}

Lahej is a governorate in south-west Yemen with a total population of 722694 and an area of $13046 \mathrm{~km}^{2}$ [9]; $95 \%$ of the population live in rural areas and the majority work in agriculture. The governorate consists of 15 districts, most of them located in the coastal areas. Lahej is one of the most advanced governorates in Yemeni in terms of implementation of health programmes. The present study was conducted in the 3 districts of Lahej that have implemented IMCI since 2003 (Tor AlBaha, Al-Madhareba-Ras-Al-Ara, and Al-Melah) [10].
The study was approved by the institutional research and ethics committee of the University Kebengsaan Malaysia (project code: FF-265-2006)

\section{Participants' enrolment}

The inclusion criteria for health providers were: trained in IMCI; in direct contact with mothers and children; and residing and working in the community for at least 2 years prior to the interview. A total of 12 health providers out of 60 officially reported IMCI-trained health providers [10] were found who fulfilled the above criteria and agreed to participate in the study. They were enrolled during the study period (January-September 2007). The minimum period of 2 years was chosen to ensure that the health provider was familiar with most of the IMCI services in Lahej. The characteristics of the participants are summarized in Table 1.

\section{Data collection}

Individual semi-structured in-depth interviews with the health providers were conducted in the IMCI casemanagement setting in 1 hospital, 4 health centres and 3 health units. These qualitative interviews were used to complement and inform a quantitative study of 1307 mother-child pairs to assess

\begin{tabular}{|c|c|c|}
\hline Qualification & Age (years) & Status \\
\hline Medical assistant & 43 & Sole IMCI provider and director of a health facility \\
\hline Nurse & 46 & Sole IMCI provider and director of a health facility \\
\hline Nurse & 35 & Sole IMCI provider and director of a health facility \\
\hline Nurse & 42 & Sole IMCI provider and director of a health facility \\
\hline Nurse & 40 & $\begin{array}{l}\mathrm{IMCl} \text { provider, director of statistics department and coordinator of } \\
\text { epidemiologic surveillance }\end{array}$ \\
\hline Medical assistant & 40 & Director of a health facility \\
\hline Medical assistant & 30 & IMCI provider and director of a health facility \\
\hline Medical assistant & 34 & $\begin{array}{l}\text { IMCl provider and coordinator, coordinator of epidemiologic surveillance } \\
\text { and provider in a general clinic }\end{array}$ \\
\hline Nurse & 29 & $\mathrm{IMCl}$ provider and director of an emergency and paediatric department \\
\hline Nurse midwife & 45 & Sole IMCI provider and reproductive health services provider \\
\hline Community midwife & 27 & Assistant IMCI provider and reproductive health services provider \\
\hline Midwife & 23 & Assistant IMCI provider and reproductive health services provider \\
\hline
\end{tabular}


child health indicators in C-IMCI. At the beginning of each interview, the purpose of the study was explained and the respondent's written consent was obtained. Health providers were assured about the confidentiality of the data and encouraged to express their opinions. Probing was used when necessary to elicit a deeper understanding of issues. The researcher interviewed the respondents using an interview guide until nothing new emerged and there was a feeling of saturation with their responses. The interviews were audiotaped and any relevant remarks were recorded in the field notes.

\section{Analysis}

Data analysis took place alongside data collection to allow questions to be refined, new avenues of inquiry to develop, and to shape the ongoing data collection. The interviews tapes were transcribed within 48 hours of the interview. To ensure data credibility and dependability, the textual data were translated separately into English language by the first researcher and the former director of the World Health Organization office in Aden. The 2 translated transcripts were reviewed together and triangulated to reach a better understanding. A content analysis was used to interpret the findings [11]. The transcript was read repeatedly and then categorized into words and phrases to find meaningful relationships between the emerging themes. This was done separately by the 2 researchers and another form of triangulation was done for the 2 analysed versions to agree on a common version.

\section{Results}

All the health providers interviewed had received IMCI training during 2002-04, except for 2 females who were informally trained by their colleagues. None of the providers had received a refresher course in IMCI. All were nurses or medical assistants. No IMCItrained physicians were enrolled in the study, as according to the interviewees it was unusual for IMCI to be practised by physicians.

The following 14 themes emerged from the interviews.

\section{1: Appreciation of clinical IMCI but vague ideas about community IMCI}

All health providers agreed that their IMCI training was very beneficial and appreciated the holistic approach. However, while they appreciated the clinical aspects of IMCI, when asked whether they had heard of C-IMCI or the key family practices, none had heard these terms, and there was speculation about whether this meant "the way to communicate with mothers".

\section{2: IMCI was working better in periph- eral health facilities than central ones}

Two medical assistants raised an important issue about how IMCI was working better in peripheral health facilities (where there are more health workers other than doctors) than central ones (where there are more doctors than other health workers). "In the health centre there are 2 clinics, one for physicians and another for the IMCI, which is run by non-doctors. Mothers, particularly educated ones, go first to the doctor then to us to take free medication. Even if doctors are trained in IMCI, they find it difficult to deal with IMCI." Also: "People sometimes do not appreciate IMCI as doctors usually prescribe more investigations and nicely packaged medications. In health units where no doctors are present, people rely on us."

\section{3: Inflexible rules, lack of integration and dissatisfaction issues}

All health providers mentioned "working difficulties" with applying ICMI. These were summarized in 2 issues.

- The huge number of papers and reports that needed to be completed. One health provider explained: "Sometimes we feel we can work better without IMCI. People in the central level insist on the reports as if it is the essence of IMCI. We are losing time and efforts in preparing reports, time which could be used in managing the child and educating the carer."

- The lack of integration between IMCI and other programmes such as the nutrition and malaria control programmes.

There were 4 issues that health providers were not satisfied with in the way they were executed:

- Distribution of mothers' counselling cards. Health facilities received insufficient numbers of cards to meet the recommendation to give one to every mother with a child under 5 years old.

- The follow-up mechanism. Health providers stated that they were working according to the IMCI follow-up plan, but that the carers sometimes did not respond, either because the child improved or because it deteriorated and they went to a hospital or private doctor in a nearby city. Some of the providers said: "We get children's news either in the markets or through social gatherings."

- The referral mechanism. Self-referral, in which carers went to a higher level health facility themselves, was common. Health providers said that they were trying to follow the rules of IMCI but sometimes this was difficult, as explained by a medical assistant: "Suppose I classify a case as pneumonia or severe febrile illness, I have to refer it to the governorate hospital. As a medical assistant, I can treat it, but according to IMCI, I have to refer it." He clarified: "If a pneumonia case comes to me in the night duty I can treat it. However, if the same case comes to the IMCI clinic I have to refer it. Meanwhile, carers usually insist on treating the child in the centre. IMCI puts restrictions that are not understandable to carers, and that need to be managed with some flexibility. I explained this during the 
supervisory visits, but they do not want to deviate from the rigid plan even if the situation requires it."

- Counselling provided by the health provider. The majority said: "We try our best to discuss with mothers maternal care, breastfeeding, child nutrition, cleanliness, how to take care of their children and when to seek care from the health facility." However, counselling was not effectively performed and different reasons were mentioned for that: "The busy work schedule; not enough time for individual counselling; overcrowding in a single room; some carers do not pay attention to what we say but are only interested in drugs."

\section{4: Poor supervisory mechanism}

All except one health provider confirmed that supervisory visits were not sufficient. The earliest follow-up visit was 3 months after completion of training and the frequency ranged from every 6 months to once a year. All of them agreed that supervision was not effective and had no feedback: "We try to explain the difficulties we meet and the things we need to perform our work such as the lack of thermometers or weight balances, but usually we do not receive any response." All except 2 health providers expressed their frustration at never being seen during the case management meetings. They had the feeling that supervisors were "looking for reports and identifying mistakes but not for assessing performance or solving work difficulties".

\section{5: Positive impact of IMCI}

Despite the difficulties, health providers viewed their IMCI experience as: "great and worthy, although what we studied is one thing and the reality is something else." "IMCI is good. The problem is that people sometimes do not welcome it as they look for doctors, investigations and commercial drugs." Health providers concluded that IMCI has made a difference in the community: "People appreciate good treatment near them", "positive response of carers to our advice", "people now pay more attention to their hygiene and nutrition of their children”. Specific impacts attributed to IMCI were mentioned: "There is a noticeable difference: more breastfeeding, less malaria and severe dehydration, no deaths from severe malnutrition or diarrhoea, severe pneumonia and referral cases are fewer, and many communicable diseases have disappeared."

\section{6: Multiple roles for one person with poor supportive infrastructure}

The majority of IMCI providers interviewed were not working exclusively for IMCI but also had other commitments. Five of the interviewed health providers were the directors of their health facilities, where they were also the sole IMCI provider. Health providers expressed the following sentiment: "Our work is fragmented and is distorted into too many duties. We are not devoting all our efforts to IMCI."

Another important feature was the work environment. IMCI was rarely practised in a separate, suitable room. In all the cases where the director of the health facility was the IMCI provider, the same room served both for administration and case management. IMCI was provided simultaneously with other services by the same health provider. Furthermore, the room could serve as the "bedroom" for the health provider. The conditions of the health facility building were variable, from a very old one at risk of collapse, to a very new one with rooms that had to be closed due to a lack of furniture and equipment. The worst aspect was the lack of water and electricity in 6 of the 8 visited facilities. The health facilities were located in districts where electricity was either absent or available only a few hours at night. The lack of water supply resulted in an inability to routinely give oral antibiotics and oral rehydration solutions in the health facility or to teach carers how to prepare it as recommended by the IMCI strategy except by sending the carer outside the facility to bring water.
Except for 2 health facilities, there were no pharmacies or clinical laboratories. This situation was complicated by the absence of private pharmacies and laboratories in most villages.

\section{7: Immunization: the most successful strategy}

Immunization appeared to be the most appreciated and most successful service under the IMCI umbrella. All health providers confirmed that there were no problems with the supply of vaccines. Health facilities were fixing certain days for immunization. Health providers spoke proudly about their work with immunization and how they sent announcements to parents, made home visits and carried out outreach activities for immunization.

\section{8: Drug supply: a disappointing issue}

The picture became different when we asked about drug supplies. Health providers confirmed that supplies of drugs on the IMCI list of free drugs was inadequate; although they were sure these were present at the central level. This defect took different forms: intermittent supply; supply of drugs that were about to expire; supply of drugs which was not proportional to the real needs; or the supply of tablets instead of syrup. Most facilities were run with only a few types of drugs. Some providers said: "We received drugs only twice since the beginning of IMCI." All of them stated that: "The last time we received drugs was 6 months back, and most of the commonly prescribed drugs are either finished or about to finish and we will not receive a new supply in the near future."

In most health facilities, there was what was called a "drug fund" to provide drugs at low cost. However, as the supplies for the drug fund were usually managed centrally, they were also subject to interruptions.

\section{9: Deficiencies in basic equipment and supplies}

Not only drugs, but also basic equipment and supplies were deficient. Only 
3 of the 8 health facilities visited had a child's weight balance. The conditions were worse in other health facilities that had no thermometer. Oral dehydration utensils were found in only 1 health facility. All facilities lacked a timing device for calculating respiratory rate.

\section{0: Different approaches to home visits}

During the study period, there were no home visitors specifically dedicated to IMCI but only for reproductive health and immunization. One medical assistant explained: "Once I trained 20 volunteers in IMCI. They were of both sexes and worked for 6 months. They sent reports for 3 months but their role became weaker and following them up became difficult as the girls got married and changed their residence. They needed motivation so that they would become more effective. This could be spiritual or financial incentives. We need to recruit married women resident in the area but this is difficult."

Health providers wondered why home visits did not include more IMCIrelated issues: "We can make home visitors also work for IMCI, such as referring children to the health facility. The problem is that we are not 'flexible, initiative or creative." They added: "Home visitors should have something to provide such as iron supplements, but they need to be supported in term of giving them incentives."

\section{1: Conflicting views about the role of health committees}

Lahej governorate has a health council at the district centre and health committees at the village level. Each usually consists of 4-5 influential persons in the community such as teachers, sheikh, imam or representative of the local authority besides the director of the heath facility. The health committee's role is to act "as a connecting body" between the health facility and the community. However, its involvement varied across the different settings: some respondents expressed positive views about the health committee while others saw it as ineffective. Positive aspects of health committees included: "It helps in malaria control and health education through supervising 3 health education volunteers." "They follow the problems of the area like water and electricity. They also communicate health messages and immunization announcements." However, it was agreed that in general the health committees and health councils were not effective in their role.

\section{2: Community participation: from very positive to very negative}

The extent of community participation ranged from strongly positive to very weak according to the health providers. In Al-Ghoul, where community members had donated the resources and built the centre, they had the feeling of "ownership of the centre". In Al-Qashaa, the community had participated in the reconstruction of the health unit by bringing water and building the fence. In contrast, people in Al-Shouba refused to pay to connect the health unit to the water supply. The picture in Al-Regaa is similar: "People want everything free. We asked them to participate in the transport costs to bring drugs but they refused."

During the study period, the most prominent form of community participation was payment for treatment: "People only pay for drugs. We tried to involve them in the health facility issues but they don't have the desire to participate. They say it is our responsibility and they look suspiciously on any possible participation and always look for the benefit behind it."

13: Community factors that facilitated or hindered good health status of children

Discussions with health providers explored factors in the community that had a potentially influential role on the health status of the community in general, and of children in particular. The positive factors can be summarized as:
- Cooperative communities that accept advice and health providers' visits to their houses.

- Peaceful communities that have no tribal conflicts or revenge issues as in some other areas in Yemen.

- People who know each other and can communicate information about child health care.

The negative factors were:

- Temporary, poor, food markets. In most visited areas, fresh fruits, vegetables and fish were brought only once per week. Grocery shops had to operate for long periods without electricity so that goods got spoiled easily.

- Lack of a continuous supply of water and electricity and public sewerage network.

- Many local residents, who were normally employed in agriculture, were idle due to scarcity of rain and the high cost of alternative water sources.

- Failure to attract the required help of international nongovernmental organizations.

- Girls were often taken out of school because families send the girls to bring water.

- Presence of nomadic communities in remote areas who lack facilities for healthy eating and good child care.

- Poverty was the norm. Unlike some other areas in Yemen there were no wealthy people or investors in the community.

\section{4: Solutions for community health problems}

Solutions identified by health providers included:

- Repairing old facilities, furnishing the newly built ones and finding convenient places for counselling.

- Allocating a special room for IMCI activities.

- Attaching pharmacies and laboratories to health facilities. 
- Training more health providers in IMCI and providing refresher courses.

- Improving the supervision mechanisms.

- Ensuring the supply of IMCI drugs and necessary equipment and supplies.

- Ensuring an electricity generator and water supply at the health facilities.

- Better integration between programmes relevant to children's health.

- Strengthening the role of the community in supporting their health facilities.

- Tackling the problem of girls' education.

\section{Discussion}

The details emerging from this qualitative exploration provide a broad vision of the context of IMCI implementation at the facility and community level. In the present study, the working environment at facilities was inadequate for providing IMCI services. Experience in other settings shows that when health providers return to their health facility after completing IMCI training, they are often faced with the realities of inadequate work environments. This is because the work environment of health providers often differs from the training setting, with shortages in personnel, drugs and supplies [12,13]. However, our situation went beyond even that and involved ruined buildings, no or inadequate rooms, a crisis in health personnel and lack of water and electricity. Lessons learnt from IMCI implementation in less-developed areas show that IMCI providers are sometimes placed in a difficult position in trying to support IMCI implementation, which suggests that IMCI guidelines are unrealistic in these areas [4]. Experience in India, for example, was that more support was required for the difficulties encountered to enable health providers to apply their new skills [12]. In fact, IMCI is not intended to be restrictive and limited to its original "presentation"; it is an umbrella for primary child health care, and is bound to evolve over the years to respond to needs in different situations [14]. Flexibility, frequent contacts, clear explanation of problems and searching for solutions can help bring higher level health personnel and IMCI implementers closer together without jeopardizing IMCI objectives [2].

An important issue raised by most interviewed health providers was the heavy workload that resulted partly from the turnover and shortage in health personnel and partly from the "diverse" work executed by them. Unfortunately, much of this work was in activities not directly related to IMCI. Benefits could be gained if these work activities were IMCI-related, such as nutrition or reproductive health services, which existed as separate vertical programmes. Akin to these findings, the IMCI analytic review found some examples of implementing IMCI in a less integrated manner [1]. This would dilute the expected benefits of the IMCI initiative, which aims to integrate the way health workers look at children while managing children's conditions [15].

IMCI guidelines recommend that a follow-up visit should be made to all trainees within 4-6 weeks of training completion. Furthermore, supervisors should visit trained health providers at least once every 6 months and this visit should include case-management observations [16]. An Ethiopian study has shown that there was a loss of skills following training, which was exacerbated when follow-up was done later than 6 months after training [17]. In India, better case management was found among a group followed up 4-6 weeks after training than a group followed up later. In addition, health workers benefitted from frequent and regular supervision [12]. In contrast, supervision in IMCI in Lahej was far from ideal.
There is no consensus in the literature on terminology for implementation and interventions to improve child health at the household and community level $[18,19]$. Our health providers were unable to identify what C-IMCI referred to. This might be expected according to evidence from the global IMCI experience $[6,7]$. One reason for this situation is that IMCI implementation focuses on training of health providers and, to a lesser, extent on health system improvement or community interventions $[2,6]$. In an analytic review of IMCI in 6 countries, none of the countries were implementing all IMCI components in a full or an integrated manner [1].

Our findings also highlighted the issue of linkages between health facilities and the communities they serve. Trusting relations and close links between health facility and community is essential $[19,20]$. However, more difficult and more important is to bring care closer to children in the form of home visits and outreach activities in the health facility catchment area; yet this is regarded as the fastest way to scale up coverage with planned interventions [21]. In the present study, home visits and outreach activities were not universal and, when present, were complementing any deficiencies in immunization and reproductive health services. Likewise, the local health councils and health committees varied widely in their role of connecting with the community, from unnoticeable to quite effective. Such variable roles may be attributed to faults in the early adoption of the community approach, such as poor understanding and readiness of the community members' role and responsibility for their health [20].

The philosophy behind C-IMCI is that many sectors influence the wellbeing of families, including water and sanitation, education, income generation, food production and local government. Therefore, alleviating illiteracy and poverty, providing clean water and generating income may all contribute to a community's ability to assure and 
sustain its health [13]. Interestingly, CIMCI has much in common with other strategies to promote economic and social development. However, it differs from these in one important respect: efforts are made to link development activities to specific key family practices. For example, improvements in water supply and sanitation need to be followed by promotion of hygiene behaviours such as handwashing and safe water storage to ensure that these improvements contribute to better child health [20]. Unfortunately, such a comprehensive understanding of $\mathrm{C}$ IMCI was not found among the visited health providers. Obviously, in the presence of so many unfavourable conditions, great efforts are needed for formal interventions to have an impact on community practices and child health. However, many of the community factors are rooted in the overall socioeconomic and developmental context of the community. Therefore, their alleviation requires long-term action from many stakeholders. Arguably, a well-functioning C-IMCI system could be very helpful $[18,19]$.

Nonetheless, all health providers appreciated the IMCI strategy and viewed it as a useful tool to manage sick children. In turn, this was reflected in improved behaviours by carers and, ultimately, a reported reduction in child morbidity and mortality, despite the lack of documented figures. Such improvements in performance are documented in studies from many countries $[2,5,12,17,22,23]$. The literature shows that IMCI has a substantial impact as it becomes better established and widespread [2,5-7].
However, others have pointed to the shortcomings of inadequate implementation of IMCI. Perhaps, the most important "inadequacy" is the failure to effectively implement C-IMCI while upgrading the skills of health workers and improving the health system $[2,3,6]$.

\section{Strengths and limitations}

The information for this study was part of the first study about IMCI implementation from the field in Yemen. Such information will help IMCI authorities and health decision-makers to identify the difficulties faced by IMCI providers that can seriously hinder successful implementation of IMCI and its potential impact on quality of care and child health outcomes. This is important in view of the accelerated pace of scalingup IMCI implementation in Yemen. However, some limitations of the study need to be addressed. As the study included only 1 Yemeni governorate implementing IMCI, the results may be prone to bias because the programme workers were also those who evaluated it. Only a very small sample of health providers were interviewed who met the inclusion criteria for the study and were available; many health providers were outside the study districts, either due to staff turnover or fulfilling other commitments in the period allocated for each district.

\section{Conclusion}

This qualitative exploration found a high appreciation of IMCI implementation and its impact on child health but only a vagueunderstanding ofC-IMCIamong health providers. The gaps that IMCI in Lahej experiences in terms of ineffective community action and insufficient health system support will endanger the positive influence of IMCI unless deliberate actions are undertaken at various levels. At the community level, initiatives to support capacity-building, community involvement and understanding, and commitment of community members towards their health and the multisectoral partnership of various development stakeholders are of the utmost importance. In order to scale-up IMCI implementation to achieve the millennium development goal of reducing child mortality, health authorities should accord high priority to fostering: full integration of vertical programmes pertinent to child health; ways to ensure better human and material resources; linkages between healthfacilityinitiatives and community-based initiatives; effective supervision; and monitoring and learning from experience, taking into account the realities of the working environments. Finally, at the academic level, practical steps to introduce IMCI pre-service training into the medical and paramedical schools in Yemen and operational research on the Yemeni IMCI experience are highly recommended.

\section{Acknowledgements}

The authors greatly appreciate the Third World Organization of Women in Science and Technology (TWOWS) for providing financial and spiritual support for this study.

\section{References}

1. The analytic review of the integrated management of childhood illness strategy. Geneva, World Health Organization, 2003.

2. Bryce J, Victora CG, MCE-IMCI Technical Advisors. Ten methodological lessons from the multi-country evaluation of Integrated Management of Childhood Illness. Health Policy and Planning, 2005, 20(Suppl. 1):94-105.

3. Huicho L et al. Implementation of the Integrated Management of Childhood Illness strategy in Peru and its association with health indicators: an ecological analysis. Health Policy and Planning, 2005, 20(Suppl. 1):32-41.

4. Victora CG et al. Integrated Management of the sick child. In: Jamison DT et al (eds). Disease control priorities in developing countries, 2nd ed. New York, Oxford University Press and World Bank, 2006:1177-1192.

5. Armstrong-Schellenberg J et al. The effect of Integrated Management of Childhood Illness on observed quality of care of 
under-fives in rural Tanzania. Health Policy and Planning, 2004, 19(1):1-10.

6. Bryce J et al. Programmatic pathways to child survival: results of a multi-country evaluation of Integrated Management of Childhood Illness. Health Policy and Planning, 2005, 20(Suppl. 1):5-17.

7. Huicho L et al. Scaling up Integrated Management of Childhood Illness to the national level: achievements and challenges in Peru. Health Policy and Planning, 2005, 20(Suppl. 1):14-24.

8. Al-Serouri A. Consultancy on development of monitoring and evaluation system for IMCl in Yemen. Sana'a, Yemen, Ministry of Public Health and Population, 2007.

9. 2005 population and housing census. Sana'a, Yemen, Central Statistical Organization, 2005.

10. The annual report of Lahej governorate, 2004. Sana'a, Yemen, Ministry of Public Health and Population, 2005.

11. Pope C, Ziebland S, Mays N. Qualitative research in healthcare: Analysing qualitative data. British Medical Journal, 2000, 320:114-116.

12. Chaudhary $\mathbf{N}$ et al. Integrated management of childhood illness (IMCI) follow-up of basic health workers. Indian Journal of Pediatrics, 2005, 72(9):735-759.

13. Pathways and partnerships: BASICS contributions to child survival. Arlington, Virginia, Basic Support for Institutionalising Child Survival, 1999.

14. Planning national implementation of IMCI. In: IMCI information package. Geneva, World Health Organization, 1999 (WHO/CHS/CAH/98.1C).

15. Bryce J et al. The multi-country evaluation of the Integrated Management of Childhood Illness Strategy: lessons for the evaluation of public health intervention. American Journal of Public Health, 2004, 94(3):406-415.

16. Guidelines for follow-up after training in the WHO/UNICEF course on IMCI for first-level health workers. Geneva, World Health Organization, 1999 (WHO/FCH/CAH/99.1).

17. Simoes EAF et al. Performance of health workers after training in integrated management of childhood illness in Gondar, Ethiopia. Bulletin of the World Health Organization, 1997, 75(1):43-53.

18. Workshop on planning and implementation of the integrated management of childhood illness community childcare component in five countries in the Eastern Mediterranean Region. Cairo, Egypt, 29 June-4 July, 2002. Cairo, World Health Organization Regional Office for the Eastern Mediterranean Region, 2003 (WHO-EM/CAH/008/E/L).

19. Regional framework for Community Integrated Management of Childhood Illness. Manila, World Health Organization Regional Office for the Western Pacific Region, 2003.

20. Winch $P$ et al. An implementation framework for household and community integrated management of childhood illness. Health Policy and Planning, 2002, 17(4):345-353.

21. World health report 2005. Make every mother and child count. Geneva, World Health Organization, 2005.

22. El-Arifeen SE et al. Quality of care for under-fives in first-level health facilities in one district of Bangladesh. Bulletin of the World Health Organization, 2005, 83(4):260-267.

23. Naimoli JF et al. Effect of the Integrated Management of Childhood Illness strategy on healthcare quality in Morocco. International Journal of Quality Health Care, 2006, 18(2):134-144. 